\title{
Utilization of Urban Health Extension Program Services and Associated Factors among Hosanna Dwellers, Hadiya Zone, southern Ethiopia: A Community Based Cross-Sectional Study
}

Birhannu Jikamo ( $\sim$ bjikammo@gmail.com )

Hawassa University College of Medicine and Health Sciences https://orcid.org/0000-0001-9491-9832

Temesegen Woelamo

Hadiya zone health department

Mekonen Samuel

Hossanna Town

Research article

Keywords: Urban Health Extension Program, Household, Utilization, Hosanna, South Ethiopia

Posted Date: August 15th, 2019

DOI: https://doi.org/10.21203/rs.2.13030/v1

License: (9) This work is licensed under a Creative Commons Attribution 4.0 International License.

Read Full License 


\section{Abstract}

Abstract Background: In 2009, in Hadiya zone reported that establishment of Urban Health Extension Program (UHEP) which is subsequent declaration of after the country of Ethiopia. Major contribution of the declared UHEP is to provide accessible service to the potentially vulnerable groups of $<5$ children pregnant women. Therefore, the aim of this study was to assess the utilization and associated factors of the urban health extension program services in Hossana Town, Hadiya Zone, southern Ethiopia, 2018 Methods: we conducted community based cross-sectional study in Hossana town, Hadiya Zone southern Ethiopia. Households were recruited by using systematic random sampling technique and study participants also by using random sampling techniques. A total of 403 study participants were participated in this study. Strength of measure of association between explanatory variables with outcome variable reported using the Odds Ratio (OR) with 95\% confidence interval. Bivariate and multivariate binary logistic regression analysis was performed to identify predictors. P-value $<0.05$ used to identify factors significantly associated with outcome variable. Results: Out of 403 households, $397(98.5 \%)$ of response rate obtained. The mean score of community knowledge about the utilization of urban health extension program service (UHEP) was 2.352 (SD \pm 1.156 . Regarding knowledge towards UHEP, of 166 (42\%) of the respondents had good knowledge towards UHEP service while 231 (58\%) had poor knowledge towards UHEP service utilization. The total number of households which graduated as a model family was 79 (19.9\%). In the adjusted multivariate model, those respondents in the age group of 36-45 year were 3.73 times(AOR $=3.73 ; 95 \% \mathrm{Cl}: 1.04-3.37)$ more likely to be utilized health extension program services as compared with those respondents in the age group of 18-24year. Those households which graduated as a model family were 2.2 times (AOR $=2.18 ; 95 \% \mathrm{Cl}: 1.36-3.51$ ) higher odds of utilized health extension program service as compared with those households which didn't graduated as a model family. Conclusions: The coverage of utilization of urban health extension program service was low in the study setting compared with previous study. There were also identified predictors that were associated with utilization of urban health extension program service.

\section{Background}

A lot of countries in sub Saharan Africa faced shortage of accessible health service specifically those economically poor families at households' level [1]. As a result of these; those families does not run effective health care service at household level to promote and prevent communicable and noncommunicable disease [1]. Due to this reason, in 2003, the government of Ethiopia launched the Health Extension Program (HEP) service which is important to provide maternal, environmental and communicable disease services at the community level [2]. Furthermore, HEP holds the package of services which includes: promotive, preventive and curative health services intention to improving individual health at community level, which is based on the standards of Primary Health Care services (PHC) $[2,3]$.

In 2009, in Ethiopia the urban health extension program was established and intention to tackle: community level health care service problem, urbanization related problem of solid and liquid waste 
management, to improve maternal and child health and urbanization related HIV/AIDs prevalence [4]. Launched program in Ethiopia help to ensure health equity at the family level regarding to essential health care service through the provision of health information dissemination at a household level and service accessibility on maternal and child health.

The health extension program in Ethiopia holds 16 packages (disease promotion, prevention and control, family health, hygiene and environmental sanitation, and health education and communication services) which provided the services at family level [4]. The health extension workers were responsible for giving the service to the communities to improve community health care services. Consecutively, Community Health Workers (CHWs) provide the service to associate the health care seekers and health extension workers which is important to facilitate accessible health care service and utilization of primary health care service [4].

Previous literatures in sub Saharan Africa indicated that plenty of people suffer from preventable morbidity and mortality that affecting the continent widely [5-7]. As a result of this, poor health care service utilization in the continent exposed to reduce young and productive age group people and which makes millions of Africans less able to survive and extends poorest societies economically in the globe [5-7]. Similar to other sub Saharan Africa countries, millions of Ethiopians vulnerable to multi-spread poverty such as: community's low educational status, inadequate access to health care service, inaccessible to adequate and clean water supply and shortage of sanitation facilities [5-7].

Due to this reason, government of Ethiopia set appropriate strategies and policies to improve utilization of health care services in the country specifically urban and rural settings [7, 8]. As a result of this, Ethiopia vastly recorded better health outcomes compared with previous health police and strategies of the country and it also improved community health outcomes at household level such as: improved maternal health and child health services, environmental health and appropriate application of primary health care service $[7,8]$.

Ethiopia is in a good way to solve urban community health problem by providing primary health care service through urban health extension professionals. Even though, speedy increasing urbanization in the country somewhat difficult to manage solid and liquid wastes appropriately and this affect the urban population's health [5]. Consequently, to minimize the urban health problem, each household member has a significant impact on the improving urban community health outcome and appropriate solid and waste management [8].

Previous literature found that the health extension program primary health care service coverage is not similar with each previous study those differences in urban and rural areas includes: community uptake of family planning service, improvement of maternal and child immunization service, $<5$ child diarrhea disease prevention and treatment, graduation of model household or open defecation free kebelle, and solid and liquid waste management practice in the country [9-12]. Nevertheless, shortage of published literature in the study setting to investigate attitude and participation level of household members 
towards health extension program service accomplishment in urban areas to improve primary health care service utilization $[11,12]$.

Shortage of published literature focusing utilization of urban health extension program service in the urban setting; for that reason, understanding associated factors with utilization of urban health extension program fills the gaps explained in the previous literatures. Therefore, the aims of this study was to assess the utilization and associated factors of the urban health extension program services in Hossana town, Hadiya Zone, southern Ethiopia, 2018

\section{Methods}

Study design and setting

We conducted community based cross-sectional study design from March 21 to April 20, 2018. Data was collected by using both quantitative and qualitative methods intended to achieve stated objectives. This study conducted in Hossana town, Hadiya zone, southern Ethiopia. It is $230 \mathrm{~km}$ far from Addis Ababa, and $160 \mathrm{~km}$ far from regional town, Hawassa, Ethiopia. According to 2007, Hosanna town census projection, estimated total population was 105,371 . Out of these, $51,632(49.47 \%)$ were male population and $53739(50.53 \%)$ were female population. Out of 53739 (50.53\%) total female population, 3,667(6.8\%) female were reproductive age group and of $3,646(6.78 \%)$ were pregnant women. There were a total of 21504 households reside in the town. There were also one hospital, three public health centers and more than 10 private higher and medium clinics were provision of health care services for the communities reside in the urban.

Study participants

Those eligible households were selected by using systematic random sampling techniques from Hosanna Town, Hadiya Zone, southern Ethiopia. The eligibility criteria were those female head of households or spouses with age greater than 18 years old and reside for more than one year in the study setting were included in the study. First select health extension worker (HEW) and then households under the health extension worker catchment areas were selected. Those head of households or spouses unable to listen, unable to talk, critically ill during data collection period were excluded from the study.

Sample size determinations and sampling procedures

Sample size was calculated using single population proportion formula for stated objective. By taking the previous proportion of $39 \%$ of utilization urban health extension program service, which is conducted in West Shoa Zone, Oromia Regional State, Ethiopia, 2014 [3], and using 95\% confidence interval with alpha value at $5 \%$ by considering $10 \%$ of non-response rate then, sample size was estimated as follow:

$N=Z 2 * P(1-P) / d 2$

$=\_(\underline{1.96}) \underline{\underline{2}}-(\underline{0.39})-(\underline{1-0.39}) .=366$ 
= 366 (with $10 \%$ for non-response a total of 403 sample size was calculated. Within each selected household, the female head (the mother or the wife) of the household was interviewed. In cases when the mother or the wife was not available, the husband (or the male head of the household) was interviewed.

Sample size determination for qualitative study participants: A total of four focus group discussions with an average of 10 study participants and 10 individual interviews were conducted. Groups were homogeneous according to the main inclusion criterion. However, there were heterogeneity within each focus group in terms of age, residence occupation and education status. Each discussion lasted average of 30 to 90 min until completion of discussion. Data saturation was sufficiently met after 4 focus group discussions and 10 individual interviews. Purposeful sampling technique was used to select the study participants which were significant to provide information representative samples to achieve stated objective.

\section{Sampling procedures:}

A systematic random sampling technique was used to select eligible households at every ten $\left(10^{\text {th }}\right)$ interval which was reside in selected kebelle in the town. All eight kebeles were included in the study. To achieve representativeness of this study, households were selected by using proportional allocation of size in each kebeles (the smallest administrative unit in Ethiopia). A list of frame of all the households in each kebeles was obtained from the kebeles administration office. If more than one eligible respondent were exist in the household's data collectors select one respondent by using lottery method. .

\section{Data collection tools and procedures}

Study instruments were adapted and modified according to the context of the study area. Thus, they could include both the outcome variables and independent variables in the structured questionnaire. Quantitative data were collected by using a structured questionnaire. The questionnaire was adapted after a review of documents, guidelines, and manuals related to UHEPs, and various previous literatures conducted in urban areas. The questionnaires had four parts. The first part was including the sociodemographic and economic characteristics of study participants; the second part was involved questions related to the community knowledge of health extension program services utilization, third part was service related contact with UHE professional's factors and the fourth part was about nature of health development army.

Qualitative data collection process includes: four focus group discussions and 10 in-depth interviews. Development of focus group discussion includes: one group formed from health extension program members eight in number, one group from kebele steering committee ten in number (8 males and 2 females), one group from kebele administrative members nine in number and other group formed from Health Development Army ten in number were participated in each sessions. Purposive sampling techniques were used to select study participants selected kebeles in Hosanna town. Participants in each 
group assuming that they had rich information regarding health extension program packages and provision of primary health care service at the community level.

\section{Data quality assurance}

The questionnaire adapted in English language and translated into working language (Amharic), then back-translated to English to check for consistency and further analysis. A pre-test was conducted in Fonko town using $5 \%$ of the study sample size and necessary adjustments were done based on pre-test findings.

Two day training was given data collectors and supervisors about the objective of the study and the process of how to collect data. Face to face interview was conducted between four trained and grade12 completed data collectors and study participants. Two Supervisors (Diploma nurses) were checking completeness and consistency of day to day collected data. In addition to this, all questionnaires were crosschecked completeness and consistency daily by the principal investigator.

For the qualitative data collection process interview guidelines prepared and used to guide the focus group discussion and one supervisor moderated the FGD. In addition to this, a tape recorder was used to record the discussions. The data was transcribed and then translated in to English for further interpretation. Similar responses was grouped and summarized based on thematic area or key variables. Results of the qualitative study were presented in narrative form triangulated with quantitative results.

\section{Data processing and analysis}

Data entered in to Epidata version 3.1 and for further analysis exported in to STATA 14. Frequency with percentage was reported to explain the amount of participants in categorical variables. Cross tabulation was performed to identify how much cell consists in each category of explanatory variable with outcome variable.

The existence of measure of association between each explanatory variable and the outcome variable identified using binary logistic regression model. In the binary logistic regression model those explanatory variables whose $p$-value $<0.25$ were the candidate predictors for the multivariate binary logistic regression model [13]. Strength of measure of association between independent variable with outcome variables reported using the Odds Ratio (OR) with $95 \%$ confidence interval. In the multivariate binary logistic regression model strength of measure of association was reported by using Adjusted Odds Ratio (AOR) with $95 \% \mathrm{Cls}$, by controlling the effect of other predictors. In multivariate binary logistic regression model, $p$-value $<0.05$ was used identify significantly associated factors with outcome variable.

The research team was checked existence of confusing variable which means confusing association between explanatory with outcome variable [14]. In addition to this, redundancy of independent variable explains the outcome variable was checked; due to its existence, concerned body made intervention on both of repeated variable produce wastage of resources, so, we removed one and made the appropriate 
intervention. Then this was evaluated by using Mean of Variation Inflation Factor (VIF) value $<10$, this indicate absence of rigorous collinearity among predictors [15].

During the analysis phase, model selection criteria performed by using log likely hood ratio test due to the reason of each model was nested with each other models. Furthermore, log likely hood ratio test was used to explain the maximum parameter estimates of parsimonious model. Moreover, reasonably fit model was selected by calculating the Hosmer and Lemeshow goodness-of-fit test which compares observed cell with expected cell tally [16]. The result of this showed that, non-significance value confirmed the data reasonable well.

\section{Results}

\section{Socio-demographic characteristics of the study participants}

A total of 403 households were interviewed: response rate of $98.5 \%$ them were interviewed. The mean age of the respondents was 43.1years old. Regarding educational status of respondents, $118(29.7 \%)$ could read and write and ethnic origin, more than half 248 (62.5\%) of them were Hadiya. concerning marital status, more than three-fourth $344(86.7 \%)$ of them were married. More than half, $252(63.5 \%)$ of the households had greater than five family size and of $237(59.7 \%)$ of respondent follow the protestant religion (Table 1)

Out of 397 households, $119(30 \%)$ of them were using latrine, while of more than of $215(54.2 \%)$ of the study participants were used family planning services in the study setting. Regarding immunization knowledge, nearly three-fourth $298(75.1 \%)$ of the study participants had know the child immunization service provided by the urban health extension worker. However, delivery service 48(12.1\%) and adolescent reproductive health services $23(5.8 \%)$ were lesser served health extension service (Table 2)

Two hundred and forty five $(61.7 \%)$ of the households were reported they had service related contact with urban health extension professionals at least once in the previous 6 months prior to the study period. The mean frequency of service related contact with urban health extension professionals was found to be $1.34( \pm 1)$ contacts per 6 months. Among those who reported a contact with urban health extension professionals, more than half $156(63.7 \%)$ of them households were reported that they were visited by the urban health extension professionals at their home (Table 3)

\section{Factors associated with community's utilization of urban health extension service}

Respondents in the age group of $36-45$ year were 3.73 times (AOR $=3.73 ; 95 \% \mathrm{Cl}$ : $1.04-13.37)$ more likely to be utilized urban health extension program service as compared with the respondent in the age group of 18-24 year. Those communities who had a good knowledge regarding urban health extension program service were 2 times $(A O R=2.01,95 \% \mathrm{Cl}: 1.20-3.58)$ more likely to be utilized the services as compared with those communities who had a poor knowledge on urban health extension program services. Those graduated model family were 2 times (AOR $=2.18 ; 95 \% \mathrm{Cl}: 1.36-3.51)$ higher odds of being utilized urban 
health extension program service as compared with those family who didn't graduated. Those household's whose monthly income were $>3550$ Ethiopian birr were 3.5 times (AOR $=3.53 ; 95 \%$ Cl: $1.63-$ 5.04 ) higher odds of being utilized urban health extension program services as compared with those household's whose monthly income reside in the range of 150-650 Ethiopian birr [table 4].

\section{Discussion}

The proportion of utilization of urban health extension service was $42 \%$. This finding is higher than the other study conducted in West Shoa zone, Ethiopia (39\%) [3]. The possible reason might be due to geographical dissimilarity and duration of starting of urban health extension program service because this study setting was urban rather than the prior one.

Knowledge on urban health extension service had significantly associated with utilization of urban health extension service. This finding is similar with other study conducted in Bishoftu town Oromia region, Ethiopia [17]. Post-natal service utilization is low in Ethiopia [18]. Despite the vigorous effort for home delivery free agenda in Ethiopia, still, knowledge of institutional service utilization low and working a lot on behavioral changes of self-health service seeking shall be considered as a linkage for improving health care delivery system in the country [18].

The graduated model family had significantly associated with utilization urban health extension services. This finding is consistent with other studies conducted in Southern Ethiopia [19] and west Gojam, Amhara region, Ethiopia [10]. The possible explanations might be due to household's have to depart through a number of steps and practices based assessment to be graduated as a 'model' family. They should be given training on health extension packages for at least three months to adopt healthy practices and serve as 'models' in their neighborhood which helps them to have improved understanding and utilization of urban health extension services. Another justification might be due to being model family increases the chance of communities utilized all urban health extension packages appropriately.

Households which had higher monthly income were significantly associated with utilization of urban health extension services as compared with low monthly income households. This finding is agreed with the other studies done in Bishoftu town [17], west Gojam,[10], in Uganda [20] and Bangladesh [21]. The similarity might be due to the existence of knowledge gaps in the community with regarding presence of high income households.

Frequently visited households by urban health extension professionals were significantly associated with utilization urban health extension service than those rarely visited households. This finding is similar with other studies conducted in West Gojam and Uganda [10,20].The usefulness of home visit programs on effectiveness of utilization of urban health extension service was mainly dependent upon the frequency of services, found that programs with more chance of contact between home visitors and their clients were most successful. 
This study had some limitations, that is to say, the associations derived from cross-sectional study have a less precise interpretation than the causal relationships derived from randomized comparisons. This study might have social desirability and recall bias by respondents to address all pertinent predictors.

\section{Conclusions}

The proportion of utilization of urban health extension service was low in the hosanna town compared with previous literature. There were also recognized predictors associated with utilization of urban health extension program services. So that, concerned bodies to mitigate the appropriate intervention.

\section{Abbreviations}

ANC- Antenatal Care, AOR-Adjusted odds ratio, BF-Breast Feeding, COR -Crude odds ratio, CSA-Central Statistical Agency, EDHS-Ethiopian Demographic and Health Survey, FMOH-Federal Ministry of Health, HDA-Health Development Army, HEP-Health Extension Program

HEW -Health Extension Worker, HH-Household

\section{Declarations}

Ethics approval and consent to participate: Ethical clearance obtained from Ethical Review Board of Wachemo University. Formal letter of permission obtained from administrative bodies of the Hadiya zone Health Department; Hosanna town administrative Health office was also secured. Finally, verbal consent was requested from every study participant included in the study during data collection time after explaining the objectives of the study and the right to withdraw from the study.

Availability of data and materials: The data that support the findings of this study was available from the corresponding author upon reasonable request in the form of Stata Version 14.

Consent for publication: Not applicable' for this section

Competing interest: We declare that we have no competing interests.

Funding: No funding was received for this study

Author's contributions: BJ, TW and MS took part in planning the study, management of quality of data, analyzes the data and writing the manuscript. All authors read and approved the final manuscript.

Acknowledgement: I would like to thank Wachamo University, College of Medicine and Health Sciences, for providing an opportunity to conduct this study.

\section{Author details:}


${ }^{1}$ College of Medicine and Health Sciences, School of Public Health, Hawassa University, Hawassa, Ethiopia

${ }^{2}$ Hadiya Zone, Health Department Disease Prevention Officer, Hadiya, Southern Ethiopia,

${ }^{3}$ Hosanna Town Communicable Disease Control Clinical Officer, Hosanna, southern Ethiopia,

\section{References}

1. Mc Auilffe E, Mac Lachlan M: Turning the Ebbing Tide: Knowledge Flows and Health in Low-income Countries. Higher Education Policy2005, 18:231-242.

2. Admassiea, A., D. Abebawa, and A. Woldemichael. 2009. "Impact Evaluation of the Ethiopian Health Services Extension Program." Journal of Development Effectiveness 1 (4): 430-449.

3. Kelbessa et al 2014 Level of health extension service utilization and associated factors among community in Abuna Gindeberet District, West Shoa Zone, Oromia Regional State, Ethiopia

4. Ethiopia Health Extension Program Evaluation Study, 2005-2007, vol. I. Household Health Survey. Addis Ababa. Center for National Health Services, 2007. Functioning of Health Posts. Addis Ababa. CSA and MACRO International. Ethiopia Demographic and Health Survey, 2005. Addis Ababa.

5. USAID/Ethiopia: End of project Evaluation for urban health extension program, April, 2012.

6. Health Extension Program: An Innovative Solution to Public Health Challenges of Ethiopia, A Case Study, USAID/Ethiopia, March 2012.

7. Marston C et al : Effects of Community Participation on Improving Uptake of Skilled Care for Maternal and Newborn Health: A Systematic, 2013.

8. World Health Organization: Working with Individuals, Families and Communities to Improve Maternal and Newborn Health, Geneva, 2003.

9. Koblinsky M et al: Responding to the maternal health care challenge, the Ethiopian Health Extension Program, 2010

10. Mezgebu Yitayal...et al, Health extension program factors, frequency of household visits and being model households, improved utilization of basic health services in Ethiopia Yitayal et al. BMC Health Services Research 2014, 14:156.

11. Berhe and Berhane: Under five diarrhea among model household and non model households in Hawassa, South Ethiopia, a comparative cross-sectional community based survey.BMC Public Health201414:187)

12. Yilkal Tafere Et al: Utilization of Environmental Health Services of Urban Health Extension Program and Associated Factors in Debretabor Town, North West Ethiopia: Cross Sectional Study. Science Journal of Public Health. Vol. 2, No. 5, 2014, pp. 494-501. doi: 10.11648/j.sjph.20140205.28.

13. David W Hosmer and Stanley Lemeshow. Applied Logistic Regression Second Edition. 2000; 95-96]. Available from: PERMREQ@WILEY.COM. 
14. ZoranBursac, et al. Purposeful selection of variables in logistic regression. Source Code for Biology and Medicine 2008 [cited 3 17]; Available from: http://www.scfbm.org/content/3/1/17.

15. G.David Garson. Testing Statistical Assumptions 2012; 44-45].Available From: Http://Www.Statisticalassociates.Com.

16. Anne Mary Hansen, Goodness-of-Fit Tests for Autoregressive Logistic Regression Models and Generalized Linear Mixed Models. 2012.

17. Ewunetu Aberra et al. Urban Health Extension Services Utilization in Bishoftu Town, Oromia Regional State, Central Ethiopia.

18. Last ten kilometer Project Ethiopia: Rapid Appraisal of Health Extension Program, Ethiopia Country Report, September 10, 2008

19. Abebe B, Mengistu K, Mekonnen T: Preliminary assessment of the implementation of the health services extension program: The case of Southern Ethiopia. Ethiop J Health Dev 2008, 22(3):302-305.

20. Lehmann U, Sanders D. Community health workers: What do we know about them? The state of the evidence on programmes, activities, costs and impact on health outcomes of using community health workers. WHO and Evidence and Information for Policy. 2007. p. 17.

21. Crigler L, Hill K, Furth R, Bjerregaard D. Community Health Worker Assessment and Improvement Matrix (CHW AIM): A Toolkit for Improving Community Health Worker Programs and Services. Published by the USAID Health Care Improvement Project. Bethesda: University Research Co., LLC (URC); 2011.

\section{Tables}

Table 1: Socio demographic characteristics of the study participants in Hosanna town, Hadiya zone, Ethiopia, 2018 


\begin{tabular}{|c|c|c|}
\hline Variables & Frequency $(\mathrm{N}=397)$ & Percentage (\%) \\
\hline \multicolumn{3}{|l|}{ Age } \\
\hline $18-24$ & 8 & 2.0 \\
\hline $25-35$ & 104 & 26.2 \\
\hline $36-45$ & 133 & 33.5 \\
\hline $46-55$ & 97 & 24.4 \\
\hline$>55$ & 55 & 13.9 \\
\hline \multicolumn{3}{|l|}{ Sex } \\
\hline Female & 301 & 75.8 \\
\hline Male & 96 & 24.2 \\
\hline \multicolumn{3}{|l|}{ Education status } \\
\hline Illiterate & 26 & 6.5 \\
\hline Able to read and write & 118 & 29.7 \\
\hline Primary(1-8) & 22 & 5.5 \\
\hline Secondary $(9-12)$ & 99 & 24.9 \\
\hline Education above certificate & 132 & 33.3 \\
\hline \multicolumn{3}{|l|}{ Marital status } \\
\hline Married & 344 & 86.7 \\
\hline Widowed/divorced/separated & 29 & 7.3 \\
\hline Single & 24 & 6.1 \\
\hline \multicolumn{3}{|l|}{ Ethnicity } \\
\hline Hadiya & 248 & 62.5 \\
\hline Kambata & 67 & 16.9 \\
\hline Amhara & 38 & 9.6 \\
\hline Gurage & 28 & 7.1 \\
\hline Silte & 16 & 4.0 \\
\hline \multicolumn{3}{|l|}{ Religion } \\
\hline Protestant & 237 & 59.7 \\
\hline Orthodox & 113 & 28.5 \\
\hline Muslim & 32 & 8.1 \\
\hline Catholic & 15 & 3.8 \\
\hline \multicolumn{3}{|l|}{ Occupation } \\
\hline Government employee & 141 & 35.5 \\
\hline House wife & 118 & 29.7 \\
\hline Merchant & 116 & 29.2 \\
\hline Farmer & 22 & 5.5 \\
\hline \multicolumn{3}{|l|}{ Family Size } \\
\hline $1-5$ & 145 & 36.5 \\
\hline$>5$ & 252 & 63.5 \\
\hline \multicolumn{3}{|l|}{ Monthly income } \\
\hline $150-650$ & 4 & 1.0 \\
\hline $651-1400$ & 26 & 6.6 \\
\hline $1401-2350$ & 49 & 12.3 \\
\hline 2351-3550 & 61 & 15.4 \\
\hline$>3550$ & 257 & 64.7 \\
\hline
\end{tabular}


Table 2: Knowledge addressed by the urban health extension professional's services in Hosanna town, Hadiya zone, Ethiopia, 2018

\begin{tabular}{lcc}
\hline Variables & Frequency $(\mathrm{n}=397)$ & Percentage (\%) \\
\hline Knowledge of HEP/Services & 166 & 41.8 \\
Good & 231 & 58.2 \\
Poor & 116 & 29.3 \\
Type of HEP/Services they know (Hygiene & Environmental sanitation) \\
Housing and environmental sanitation & 119 & 30 \\
Latrine construction and use & 102 & 25.7 \\
Water supply and food safety measure & 60 & 15 \\
Solid and liquid waste Management & & \\
Family health services & 298 & 75.1 \\
Immunization advice & 215 & 54.2 \\
Family planning & 79 & 19.9 \\
Nutrition counseling & 59 & 14.9 \\
Antenatal care & 48 & 12.1 \\
Pregnancy care and Delivery service & 23 & 5.8 \\
Adolescent reproductive health & & \\
Disease prevention and control & 178 & 44.8 \\
HIV/AIDS/TB/STI prevention and control & 219 & 55.2 \\
Malaria prevention and control & & \\
\hline
\end{tabular}

Table 3: Nature of contact/visit of household's by urban health extension program service, Hosanna town, Hadiya zone, Ethiopia, 2018

\begin{tabular}{lll}
\hline Variables & Frequency (N) & Percentage (\%) \\
\hline Presence of HEWs visit/contact in the previous 6 months & & \\
yes & 245 & 61.7 \\
no & 152 & 38.3 \\
Place of contact & & \\
at home & 156 & 63.7 \\
at health post/kebele & 50 & 20.4 \\
at community meeting & 30 & 12.2 \\
Other place specify: church, cultural place & 9 & 3.7 \\
when was last time UHEPs visited your home & & \\
less than one month ago & 94 & 60.3 \\
two month ago & 34 & 21.8 \\
Three month ago & 15 & 9.6 \\
more than three month ago & 3 & 1.9 \\
more than four month ago & 4 & 2.6 \\
more than five month ago & 6 & 3.85 \\
\hline
\end{tabular}

Table 4:-Bivariate and Multivariate logistic regression analysis of independent factors associated with utilization of urban health extension service in Hossana town, Hadiya zone Ethiopia, 2018 


\begin{tabular}{|c|c|c|c|c|}
\hline \multirow[t]{2}{*}{ Variables } & \multicolumn{2}{|c|}{$\begin{array}{c}\text { Urban health extension service } \\
\text { utilization }\end{array}$} & \multirow[t]{2}{*}{ COR $(95 \% \mathrm{CI})$} & AOR (95\% CI) \\
\hline & Utilized & Not utilized & & \\
\hline \multicolumn{5}{|l|}{ Age of respondent } \\
\hline $18-24$ & 5 & 9 & 1 & 1 \\
\hline 25-35 & 53 & 65 & $0.68(0.30-3.53)$ & $2.31(.07-7.55)$ \\
\hline $36-45$ & 74 & 59 & $\begin{array}{l}1.14(0.79- \\
6.05)^{* *}\end{array}$ & $3.73(1.04-13.37)^{* * *}$ \\
\hline $46-55$ & 49 & 35 & $\begin{array}{l}1.34(0.59- \\
6.03)^{*}\end{array}$ & $1.39(0.46-4.17)$ \\
\hline$>55$ & 32 & 16 & $0.7(0.50-3.75)$ & $2.81(0.89-8.87)$ \\
\hline \multicolumn{5}{|l|}{ Education status } \\
\hline Illiterate & 27 & 37 & $0.99(0.32-.39)$ & $0.70(0.25-2.02)$ \\
\hline Read and write & 25 & 34 & $1.21(0.32 .48) *$ & $1.24(0.44-3.53)$ \\
\hline Primary(1-8) & 40 & 66 & $0.78(0.28-1.06)$ & $0.43(0.17-1.06)$ \\
\hline Secondary(9-12) & 42 & 54 & $0.73(0.37-1.41)$ & $0.71(0.31-1.63)$ \\
\hline $\begin{array}{l}\text { Education } \\
\text { certificate }\end{array}$ & 37 & 35 & 1 & 1 \\
\hline \multicolumn{5}{|l|}{ Marital status } \\
\hline Married & 220 & 57 & $\begin{array}{l}2.57(0.50- \\
2.18)^{*}\end{array}$ & $0.84(0.35-1.99)$ \\
\hline \multicolumn{5}{|l|}{ Family Size } \\
\hline $1-5$ & 102 & 59 & 1 & 1 \\
\hline 5-9 & 76 & 61 & $\begin{array}{l}1.39(0.66- \\
1.94)^{*}\end{array}$ & $1.12(0.63-2.01)$ \\
\hline$>9$ & 67 & 32 & $0.59(1.22-5.7)$ & 3.01(0.33-6.83) \\
\hline \multicolumn{5}{|c|}{ House hold income (Etbirr) } \\
\hline $150-650$ & 81 & 11 & 1 & 1 \\
\hline $651-1400$ & 170 & 22 & $0.95(0.068-4.04)$ & $0.92(0.33-2.59)$ \\
\hline 2351-3550 & 92 & 5 & $0.41(0.18-0.85)$ & $0.40(0.19-1.86)$ \\
\hline$>3550$ & 14 & 2 & $2.63(2.831,7.005)^{* *}$ & $\begin{array}{l}3.53(1.630- \\
5.04)^{*}\end{array}$ \\
\hline \multicolumn{5}{|c|}{ knowledge of HE Packages in the community } \\
\hline Good & 119 & 7 & $1.31(2.203-5.106)^{*}$ & $\begin{array}{l}2.01(1.20-3.57) \\
*\end{array}$ \\
\hline Poor & 117 & 9 & 1 & 1 \\
\hline \multicolumn{5}{|l|}{ Graduated Model family } \\
\hline Yes & 130 & 41 & $2.26(1.42,3.32)^{* *}$ & $\begin{array}{l}2.18(1.36- \\
3.51)^{* * *}\end{array}$ \\
\hline No & 132 & 94 & 1 & 1 \\
\hline \multicolumn{5}{|c|}{ Frequency of total contact in the last 6 months } \\
\hline Yes & 184 & 28 & $3.31\left((1.19-6.38)^{*}\right.$ & $1.68(1.03-1.83)^{* * *}$ \\
\hline No & 123 & 62 & 1 & 1 \\
\hline
\end{tabular}

Note: ${ }^{*}$-significant results 1-reference category. Statistical significant $\left({ }^{*} p<0.05\right)$, strongly significant $\left({ }^{* *} p \leq 0.001\right) * * * p \leq 0.0001$ 